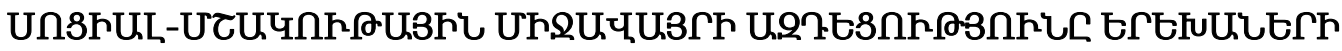

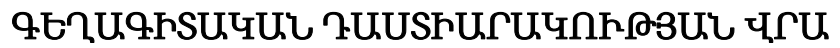

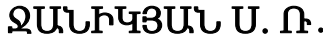

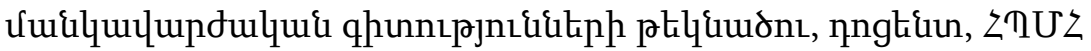

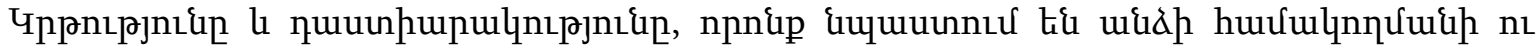

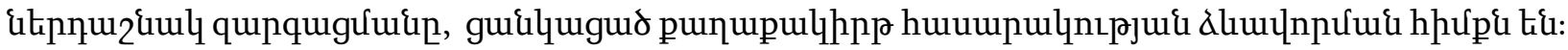

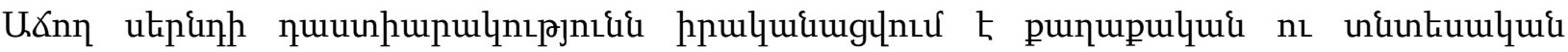

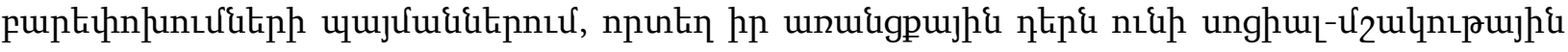
uhquulujn:

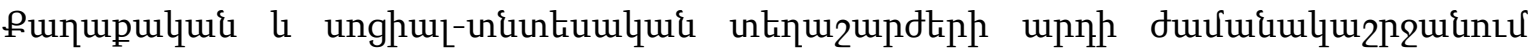

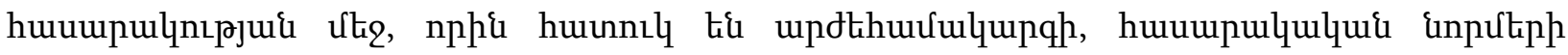

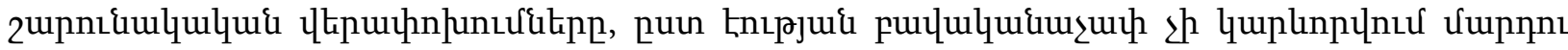



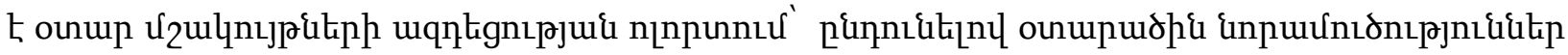

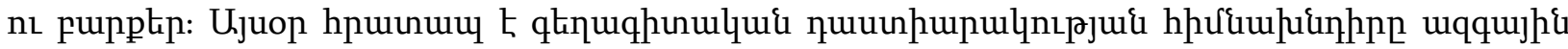

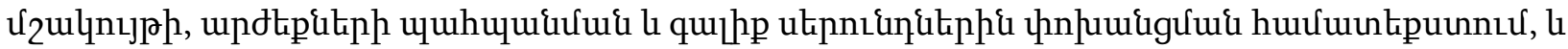

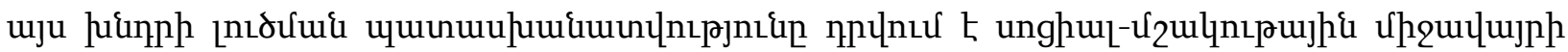

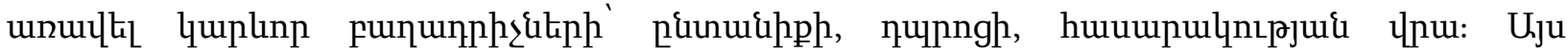

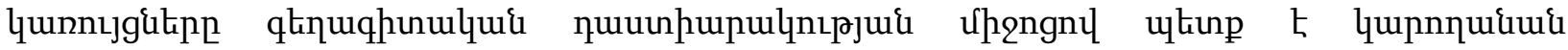

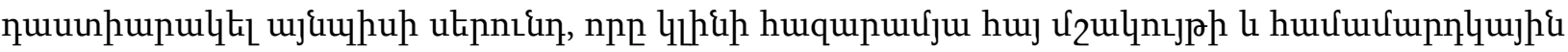

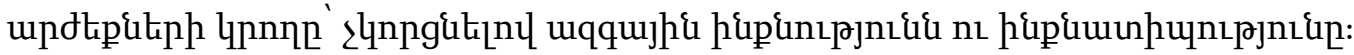

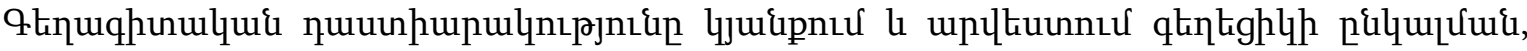

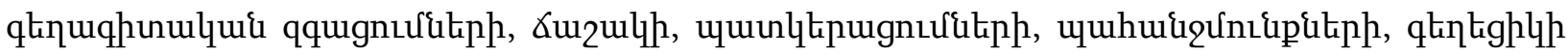

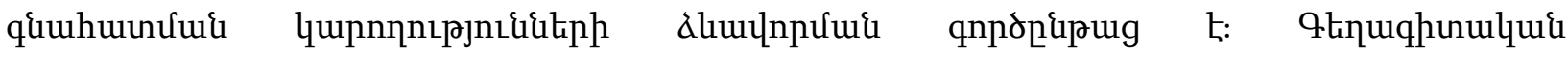

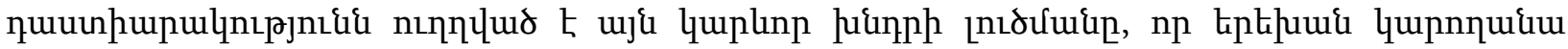

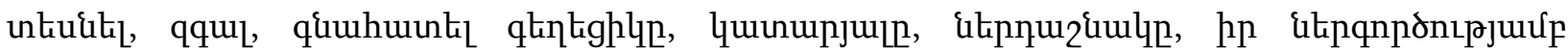

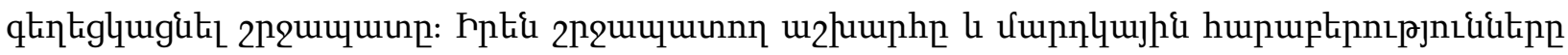

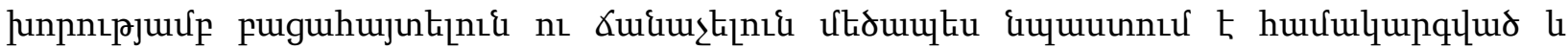

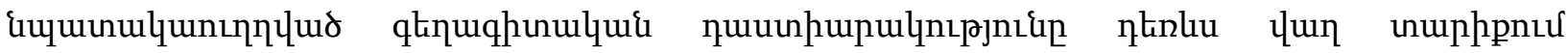

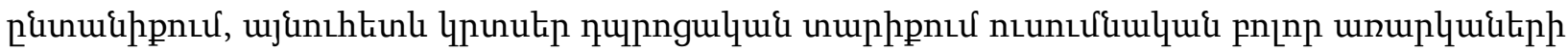

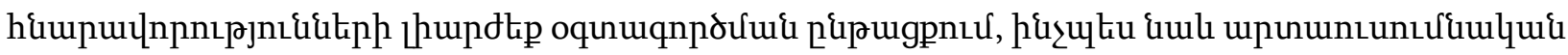




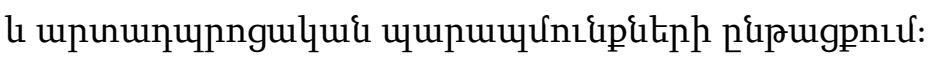



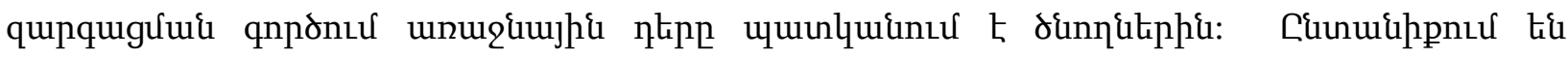



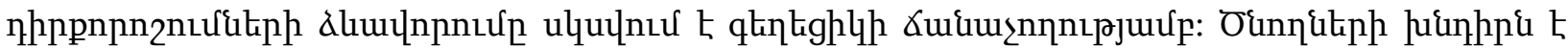

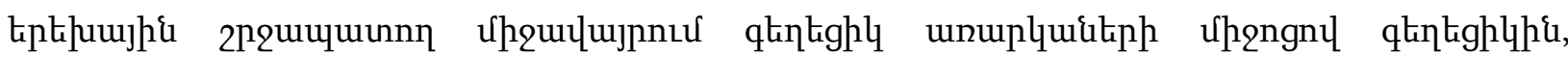

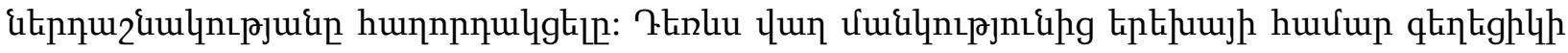

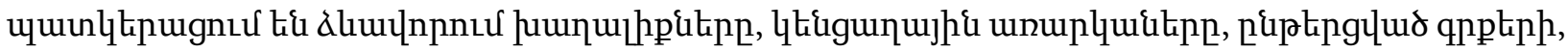

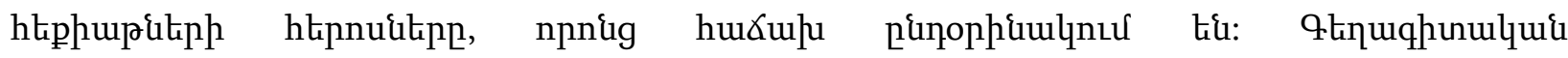

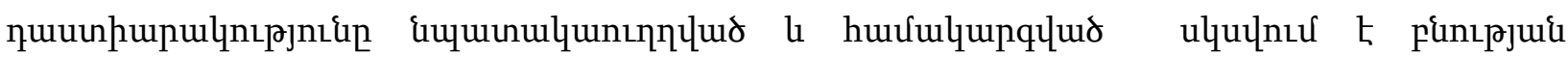

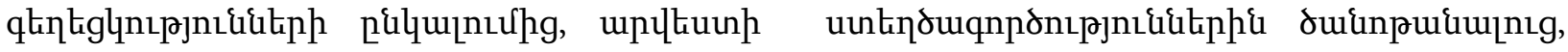

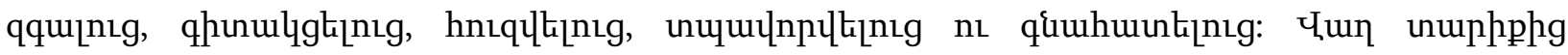

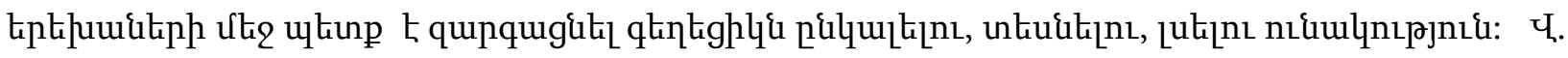

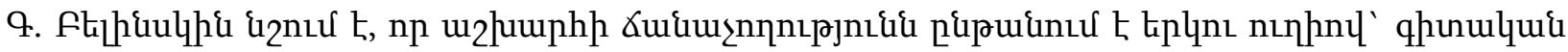

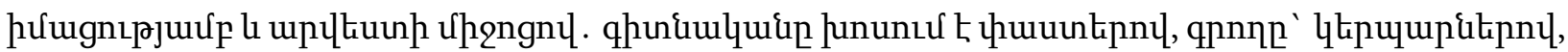

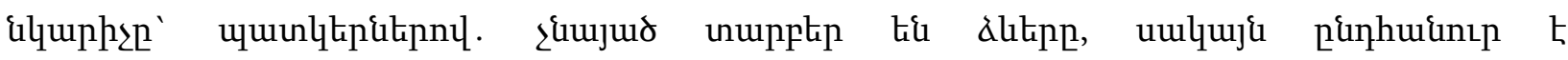

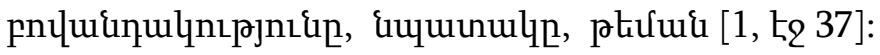

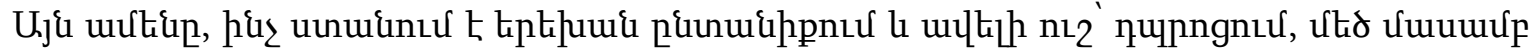

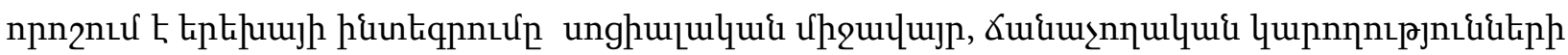

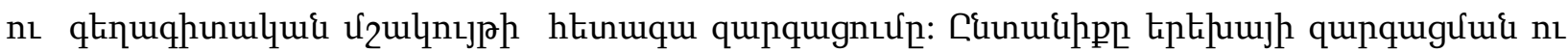

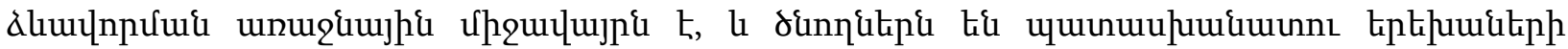

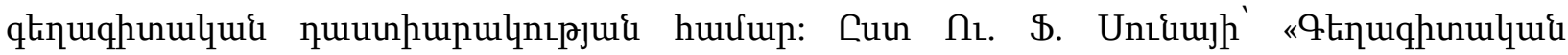

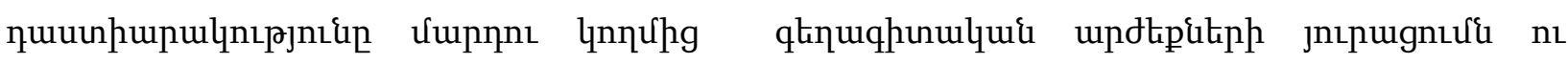

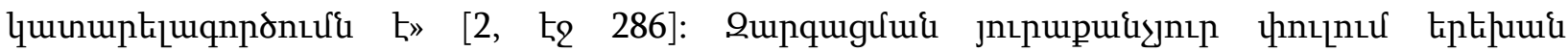

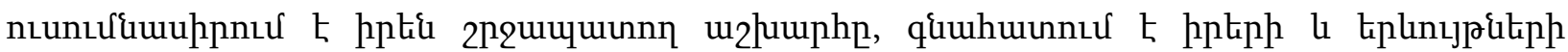

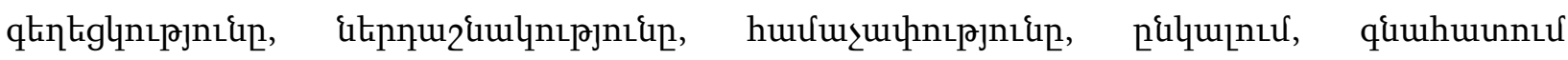

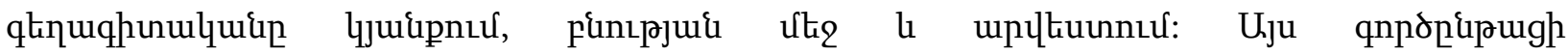

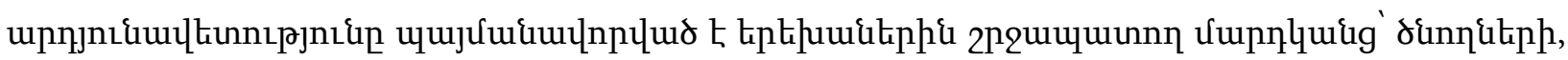

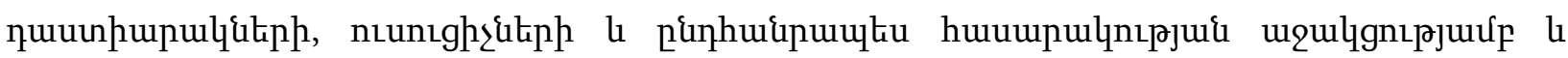

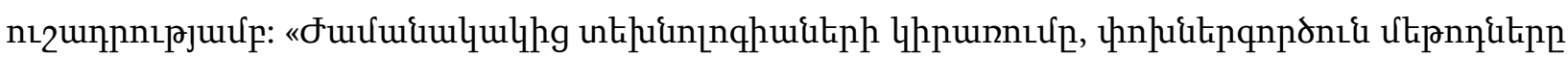

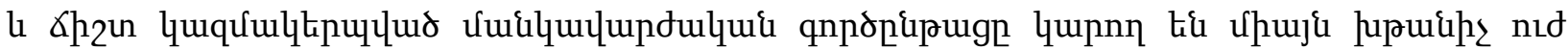

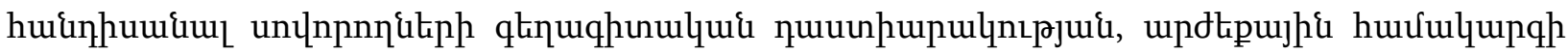

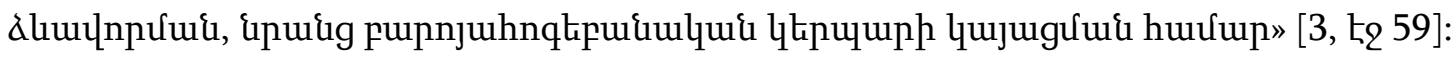




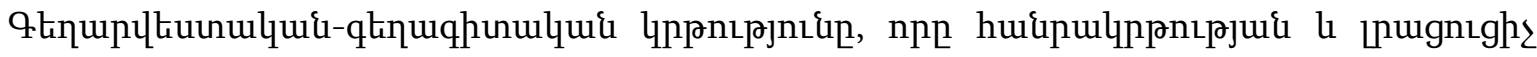

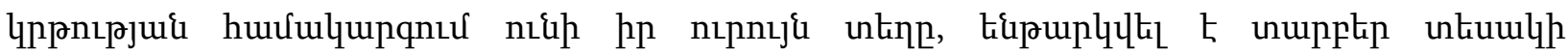

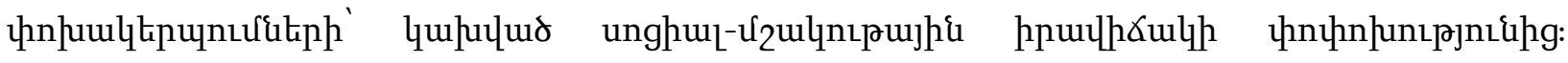

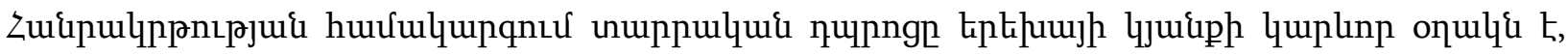

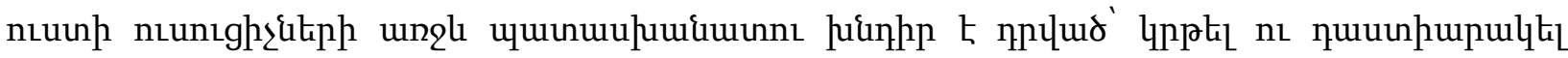

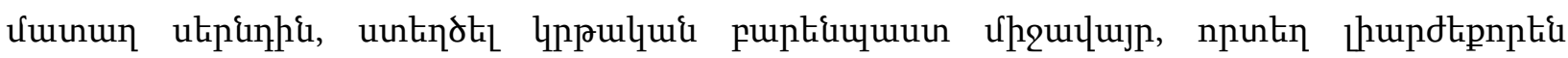

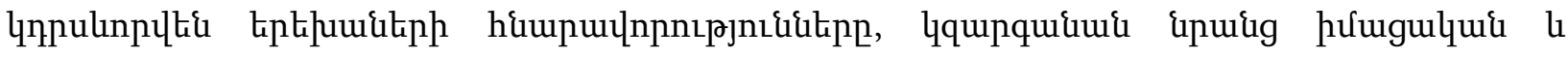

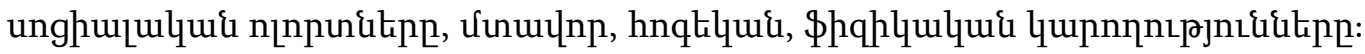

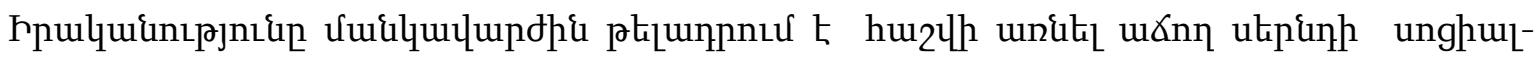

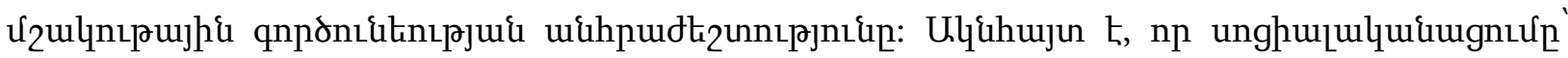

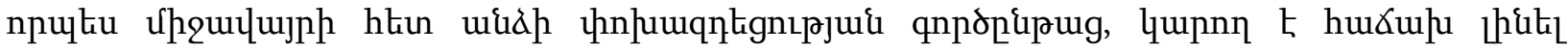

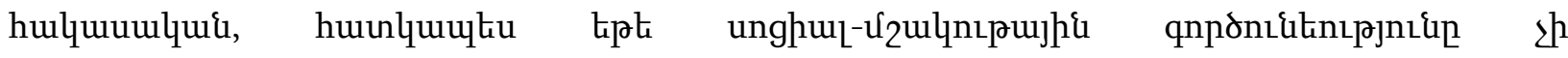



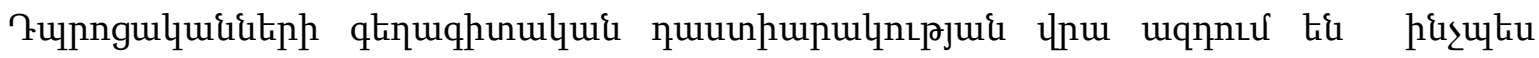

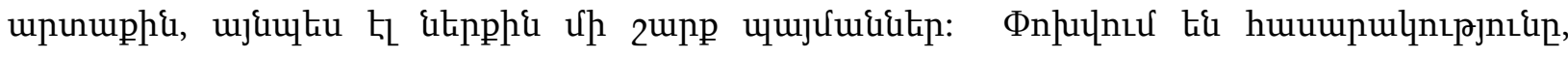

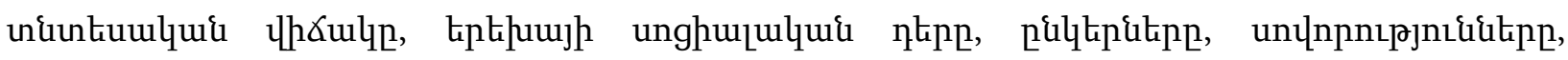

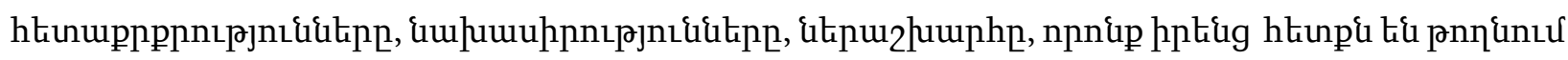

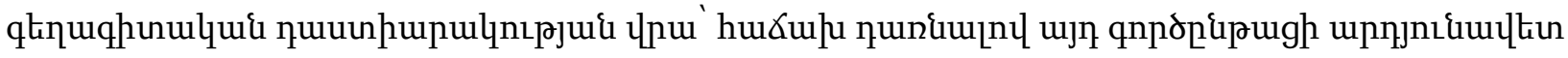



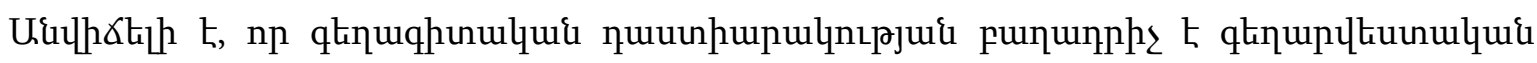

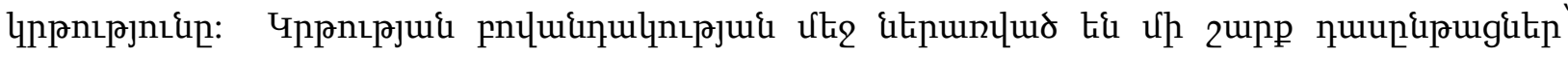

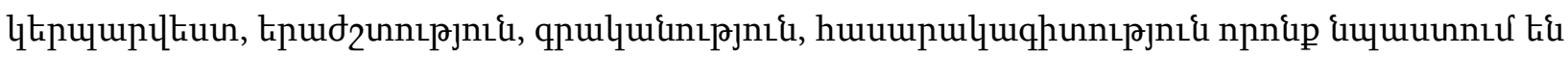

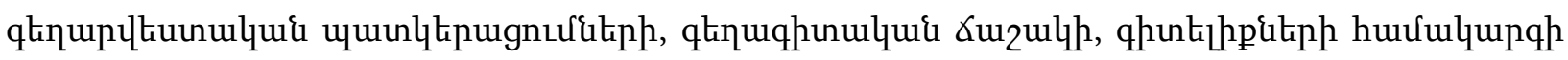

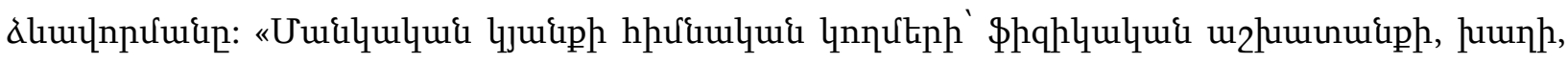

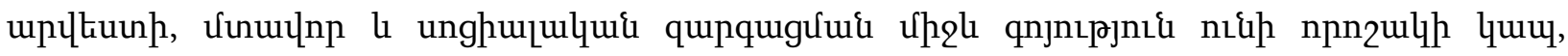

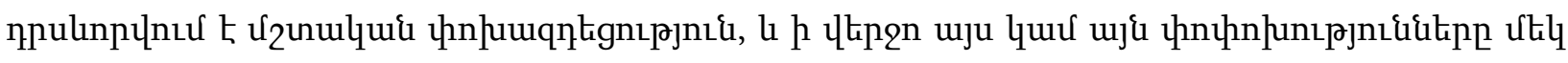

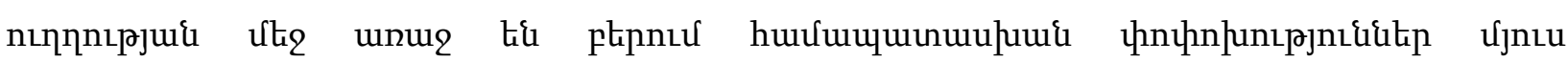

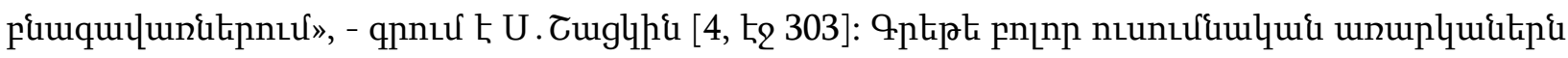

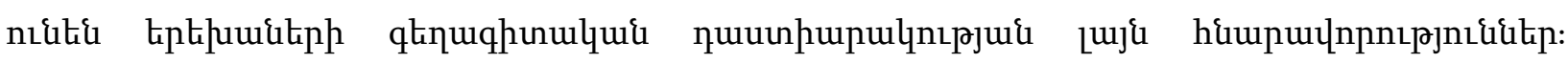

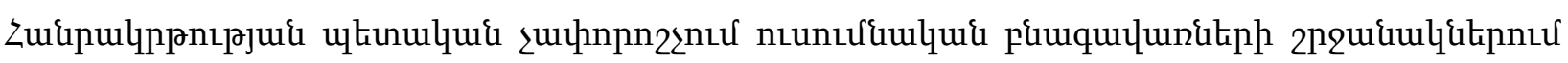

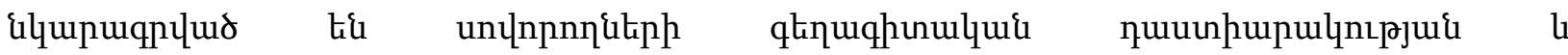

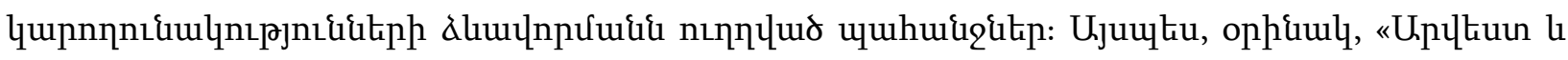

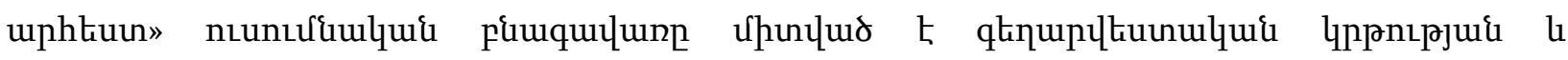




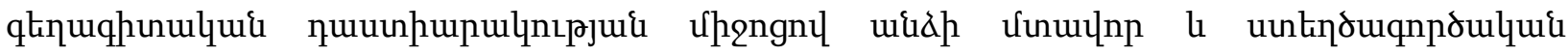

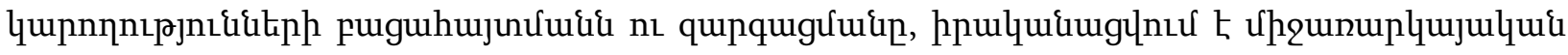



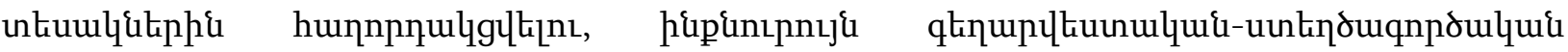

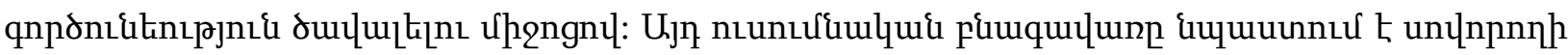

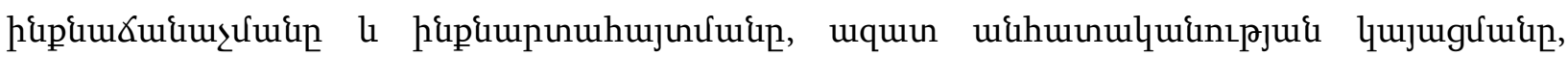

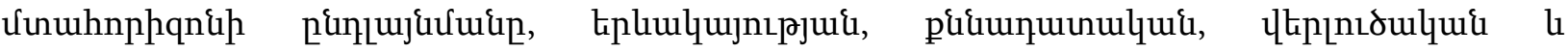

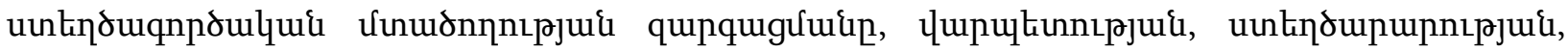

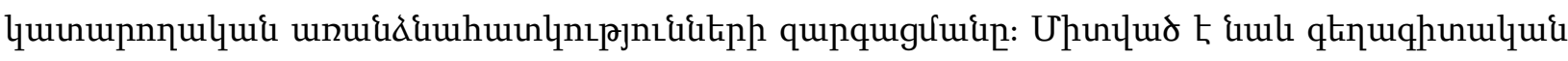

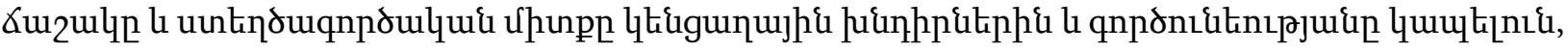

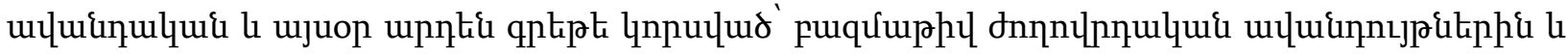

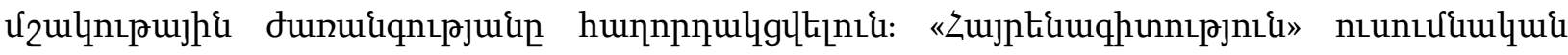

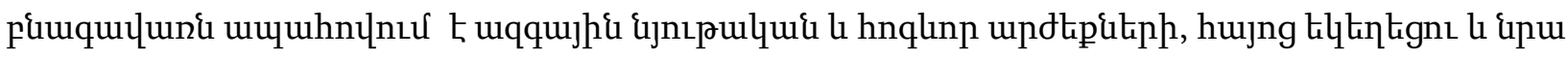

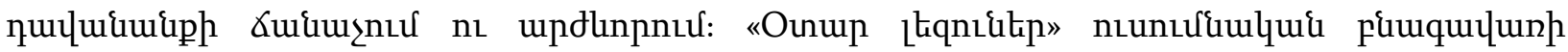

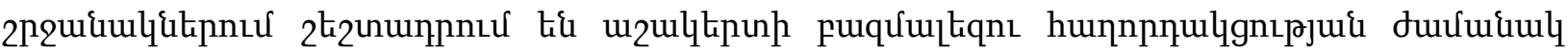

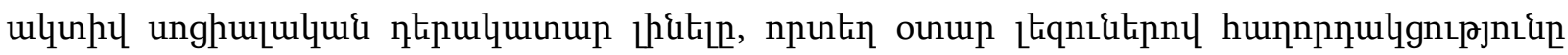

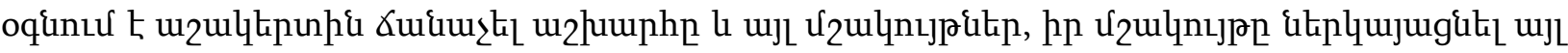

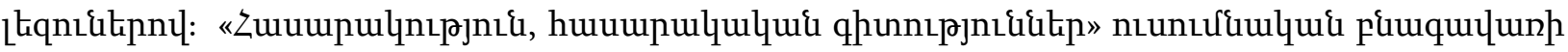

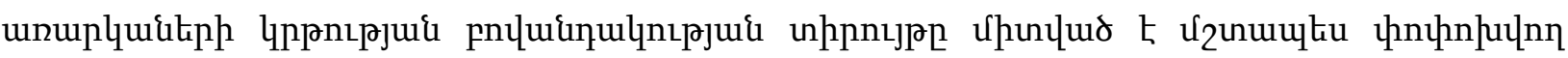

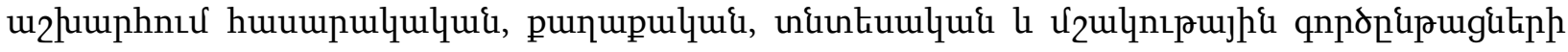

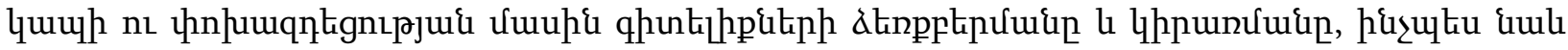

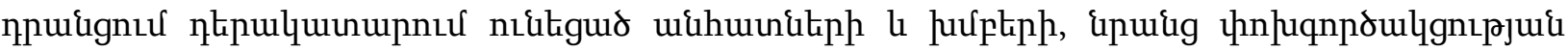

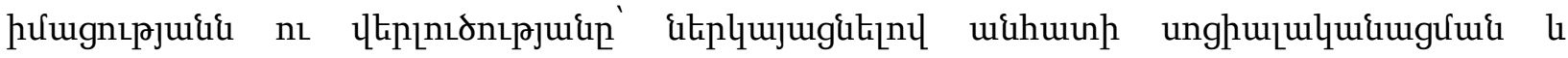

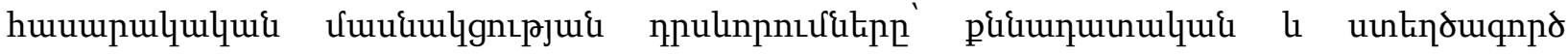

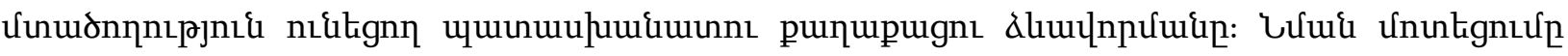

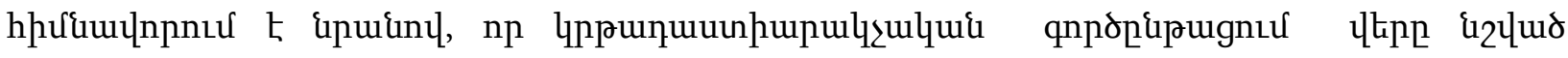

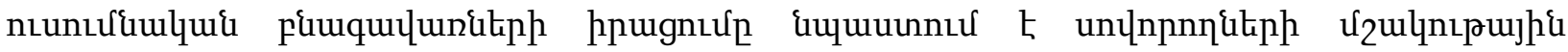



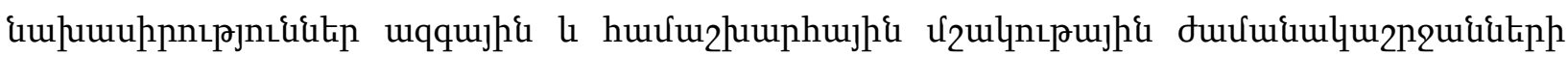

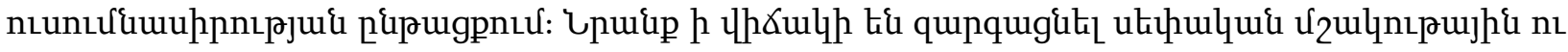

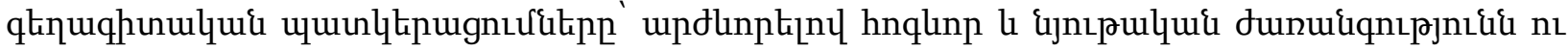

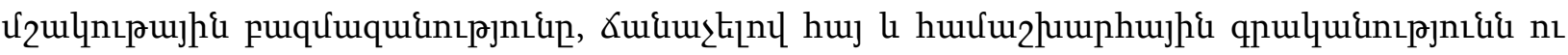

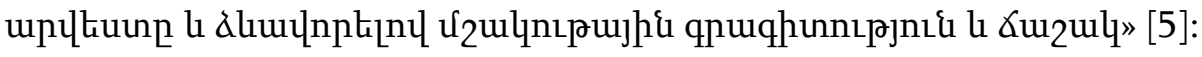




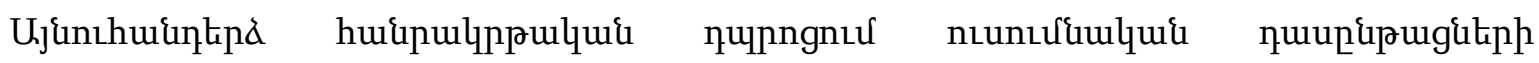

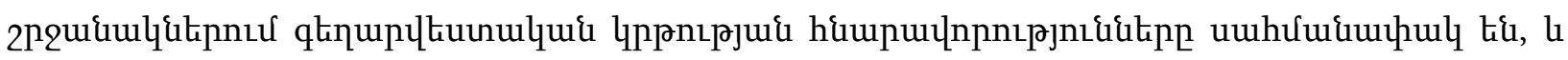

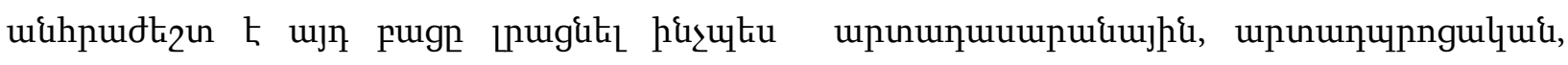

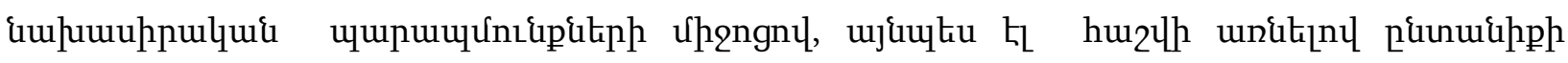
nuuunhupulıulquid \&lipnıdn:

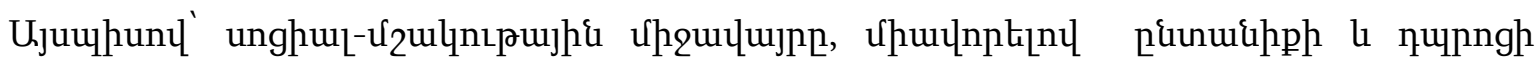

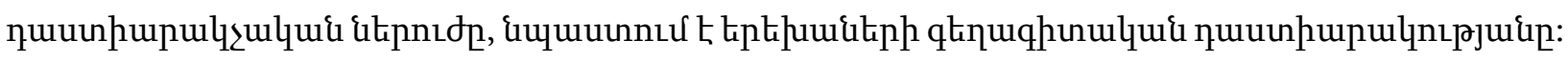

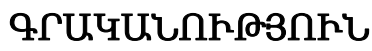

1. Якушева С.Д., Формирование эстетической культуры студентов колледжа. Монография.-Оренбург: РИК ГОУ ОГУ, 2004, -170 с.

2. Суна У.Ф. Эстетическая культура студента: опыт социологического анализа.-М., Педагогика, 1977, -124 с.

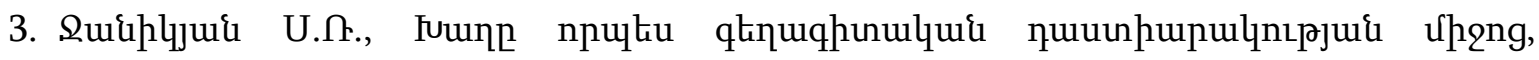

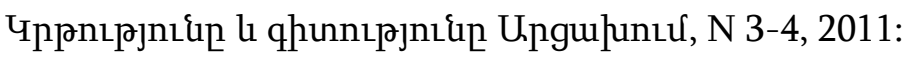

4. Шацкий Ц.Т., Избранные педагогические сочинения. Том 1, -М. . , 1980, -304 с

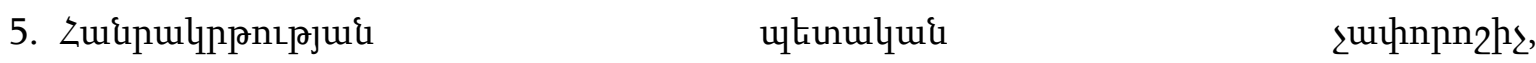
https://www.arlis.am/documentview.aspx?docid=149788

\section{IMPACTS OF SOCIO-CULTURAL ENVIRONMENT ON CHILDRENS' AESTHETIC UPBRINGING PROCESS}

The article considers the role of socio-cultural environment as a critical condition for the formation and development of a person. The impacts of school and family on children's aesthetic upbringing process are presented and revealed.

Keywords: comprehensive and harmonious development of a person, upbringing, aesthetics, environment, socialization. 